\title{
Transcriptome Fingerprints Distinguish Hallucinogenic and Nonhallucinogenic 5-Hydroxytryptamine 2A Receptor Agonist Effects in Mouse Somatosensory Cortex
}

\author{
Javier González-Maeso, ${ }^{1}$ Tony Yuen, ${ }^{1}$ Barbara J. Ebersole, ${ }^{1}$ Elisa Wurmbach, ${ }^{1}$ Alena Lira, ${ }^{4}$ Mingming Zhou, ${ }^{4}$ \\ Noelia Weisstaub, ${ }^{4}$ Rene Hen, ${ }^{5}$ Jay A. Gingrich, ${ }^{4}$ and Stuart C. Sealfon ${ }^{1,2,3}$ \\ ${ }^{1}$ Department of Neurology, ${ }^{2}$ Fishberg Center for Neurobiology, and ${ }^{3}$ Department of Pharmacology and Biological Chemistry, Mount Sinai School of \\ Medicine, New York, New York 10029, and ${ }^{4}$ Department of Psychiatry and ${ }^{5}$ Center for Neurobiology and Behavior, Columbia University, New York, \\ New York 10032
}

\begin{abstract}
Most neuropharmacological agents and many drugs of abuse modulate the activity of heptahelical G-protein-coupled receptors. Although the effects of these ligands result from changes in cellular signaling, their neurobehavioral activity may not correlate with results of in vitro signal transduction assays. 5-Hydroxytryptamine 2A receptor (5-HT2AR) partial agonists that have similar pharmacological profiles differ in the behavioral responses they elicit. In vitro studies suggest that different agonists acting at the same receptor may establish distinct patterns of signal transduction. Testing this hypothesis in the brain requires a global signal transduction assay that is applicable in vivo. To distinguish the cellular effects of the different 5-HT2AR agonists, we developed an assay for global signal transduction on the basis of high throughput quantification of rapidly modulated transcripts. Study of the responses to agonists in human embryonic kidney 293 cells stably expressing 5-HT2ARs demonstrated that each agonist elicits a distinct transcriptome fingerprint. We therefore studied behavioral and cortical signal transduction responses in wild-type and 5-HT2AR null-mutant mice. The hallucinogenic chemicals ( \pm )-2,5-dimethoxy-4-iodoamphetamine (DOI) and lysergic acid diethylamide (LSD) stimulated a head-twitch behavioral response that was not observed with the nonhallucinogenic lisuride hydrogen maleate (LHM) and was absent in receptor null-mutant mice. We also found that DOI, LSD, and LHM each induced distinct transcriptome fingerprints in somatosensory cortex that were absent in 5-HT2AR null-mutants. Moreover, DOI and LSD showed similarities in the transcriptome fingerprints obtained that were not observed with the behaviorally inactive drug LHM. Our results demonstrate that chemicals acting at the 5-HT2AR induce specific cellular response patterns in vivo that are reflected in unique changes in the somatosensory cortex transcriptome.
\end{abstract}

Key words: 5- $\mathrm{HT}_{2 \mathrm{~A}}$ receptor; hallucinogen; LSD; serotonin; signal transduction; somatosensory cortex

\section{Introduction}

The effects of 5-hydroxytryptamine [serotonin (5-HT)] are mediated by a large number of receptor subtypes, most of which belong to the rhodopsin-like heptahelical structural family (Barnes and Sharp, 1999). The 5- $\mathrm{HT}_{2 \mathrm{~A}}$ receptor (5-HT2AR) has been implicated in the symptoms of schizophrenia, and antagonism at 5-HT2ARs has been proposed to contribute to the clinical effects of "atypical" antipsychotic medications (Meltzer, 1999). Activation of 5-HT2ARs is thought to be responsible for the psychotomimetic properties of hallucinogenic chemicals (Aghajanian and Marek, 1999a). For example, many of the behavioral responses induced by hallucinogenic drugs of abuse, such as LSD, depend on activation of 5-HT2ARs (Fiorella et al., 1995; Nichols, 1997; Willins and Meltzer, 1997; Vollenweider et al., 1998). In

\footnotetext{
Received March 13, 2003; revised Aug. 1, 2003; accepted Aug. 1, 2003.

This work was supported by National Institutes of Health Grant P01-DA12923. J.G.-M. was the recipient of a postdoctoral fellowship from the Basque Government. We thank Drs. R. lyengar and R. Mitchell for critical reading of this manuscript and helpful discussion and Irina Ivanova for expert technical assistance.

Correspondence should be addressed to Dr. Stuart C. Sealfon, Department of Neurology, Box 1137, Mount Sinai School of Medicine, One Gustave L. Levy Place, New York, NY 10029. E-mail: stuart.sealfon@mssm.edu. Copyright $\odot 2003$ Society for Neuroscience $\quad$ 0270-6474/03/238836-08\$15.00/0
}

contrast, closely related chemicals that have similar pharmacological activity at the 5-HT2AR in vitro (Egan et al., 1998; Porter et al., 1999) do not induce similar neuropsychological responses (Pieri et al., 1978; White and Appel, 1982). Therefore, the mechanisms through which specific 5-HT2AR agonists elicit such profound alterations in cognition, perception, and mood remain poorly understood.

Most therapeutic drugs and many drugs of abuse interact with heptahelical receptors, and the effects of these ligands result from changes in receptor conformation that modulate cellular signaling responses. Many heptahelical receptor subtypes can couple to multiple signaling pathways (Jordan et al., 2000), and specific agonists acting at the same receptor have been discovered to vary in their relative efficacy at activating these downstream signals (Berg et al., 1998). This suggests that agonists induce distinct receptor conformations that preferentially activate specific signaling pathways, a hypothesis called agonist trafficking of receptor signaling (Kenakin, 1995). Support for agonist signal trafficking has been obtained in tissue culture experiments with heterologous expression of heptahelical receptors (Berg et al., 1998; Cordeaux et al., 2001; Cussac et al., 2002); however, the 
relative stoichiometry of the receptors to other signaling components in recombinant cell lines may differ from that found in vivo and may cause anomalies in the pharmacological responses that are assayed (Kenakin, 1997). The ability to measure agonist signal trafficking in the brain, for which there is not yet evidence, would have important implications for understanding the mechanism of action of neuroactive chemicals and for the development of specific neuropharmacological therapeutics. The behaviorally distinct effects of 5-HT2AR agonists provide a compelling experimental system for studying drug-specific signaling effects in vivo.

Signal transduction measurements are difficult to obtain in complex target tissues, and assays of a single signaling pathway often correlate poorly with the neurobehavioral effects of specific agonists (Egan et al., 1998). To provide a bridge between cellular activity and behavioral responses, we studied the effects on gene expression of receptor activation by different agonists. Most signaling pathways regulate gene expression in response to extracellular cues (Clayton, 2000), and receptor activation can cause concentration-dependent changes in the level of induction of specific genes (Yuen et al., 2002a,c). Gene reporter constructs are widely used for monitoring the responses to activation of heptahelical G-protein-coupled receptors (Hill et al., 2001). We reasoned that endogenous mRNA expression could provide a global assay of changes in the signaling network that would be useful both in vitro and in vivo to monitor agonist-specific intracellular and intercellular signal processing.

To elucidate the mechanism of action of 5-HT2AR agonists, we used high throughput gene expression assays to quantify the global cellular responses induced in vitro and in vivo. To our knowledge, quantification of changes in gene expression has not been used previously to differentiate agonist responses acting at the same receptor. Therefore, we first evaluated this approach using a standard in vitro pharmacological model, a stable cell line expressing the 5-HT2AR. We quantified the concentrationdependent gene changes to various agonists in human embryonic kidney 293 (HEK293) cells expressing the human 5-HT2AR (198A2) to demonstrate that gene quantification could provide a sensitive and agonist-specific readout of signal transduction responses to receptor activation. Having validated this assay in a cell line expression system, we then adapted this transcriptome signaling assay method to investigate the 5-HT2AR-dependent responses elicited by different agonists in mouse somatosensory cortex (SSCx) in vivo.

\section{Materials and Methods}

Cell lines and DNA constructs. The construct for the wild-type human 5-HT2AR was prepared as described previously (Ebersole et al., 2003). The insert was subcloned from pAlter (Promega, Madison, WI) by SmaI$\mathrm{Xba \textrm {I }}$ digestion. For expression, the insert was subcloned into the EcoRV and $\mathrm{XbaI}$ sites of pcDNA3 (Invitrogen, Carlsbad, CA). For functional studies, clonal stable cell lines were derived by transfection of HEK293 cells, as described previously (Ebersole et al., 2003). The 5-HT2ARexpressing HEK293 cell line (198A2) expresses $\sim 200 \mathrm{fmol} / \mathrm{mg}$ protein of human wild-type 5-HT2AR (Ebersole et al., 2003).

Sources of chemicals. For cell and mice treatments, 5-HT, 5-methoxytryptamine, tryptamine, DOI, LSD, and LHM were obtained from Sigma (St. Louis, MO).

Cell-line drug treatment and processing. For quantitative real-time PCR (qRT-PCR) experiments, on day 1, cells were seeded in 24-well Biocoat (Becton Dickinson, Bedford, MA) multiplates at a density of 200,000 cells per well. On day 2, cells were switched to serum-free medium. On day 3 , cells were treated with the indicated concentrations of agonist in serum-free medium and returned to the tissue culture incubator for 60 $\min$ at $37^{\circ} \mathrm{C}$. Treatment was terminated by aspiration of the incubation medium and application of $370 \mu \mathrm{l}$ of lysis buffer containing guanidinium thiocyanate as described previously (Yuen et al., 2002b). Isolation of RNA (performed in 96-well format using Strataprep96; Stratagene, La Jolla, CA), reverse transcription, and qRT-PCR were performed as described previously (Yuen et al., 2002b). For oligonucleotide array analysis, cells were seeded in $15 \mathrm{~cm}$ culture dishes at a density of $12 \times 10^{6}$ cells per plate. On day 2, medium was switched as described above. On day 3 , cells were treated for $60 \mathrm{~min}$ with $10 \mu \mathrm{M}$ 5-HT. Cells were harvested with $10 \mathrm{ml}$ guanidinium thiocyanate lysis buffer, and total RNA was isolated by the method of Chomczynski and Sacchi as described previously (Yuen et al., 2002b). Baseline levels of gene expression were stable for the duration of these experiments.

Oligonucleotide microarray probe labeling and hybridization. Probe labeling and hybridizations were performed as described previously (Yuen et al., 2002b). A total of nine arrays were used (five with vehicle-treated samples and four with 5-HT-treated samples). Pairwise comparison was done between all possible vehicle-treated versus 5-HT-treated sample pairs to generate the relative levels of expression of each transcript.

Generation of the 5-HT2AR null-mutant mice. The null-mutation mice for the 5-HT2AR were generated as detailed previously (Gingrich et al., 1999). The mutant mice have no detectable changes in brain development or cytoarchitecture (A. Lira, M. Zhou, and J. Gingrich, unpublished data).

Behavioral studies. Subjects used in behavioral experiments were 5-HT2AR wild-type and null-mutant mice of 129 Sv background. Animal care and all experimental procedures were approved by the Institutional Animal Use and Care Committee. They were bred and raised in our facility and maintained on a $12 \mathrm{hr}$ light/dark cycle (lights out at 8 P.M.). All subjects were offspring of heterozygote breeding. Twenty-four wildtype and 24 mutant native 12-week-old male mice weighing 23-33 gm were used in this experiment. Animals were group housed: two wild-type and two mutant per cage. Behavioral testing took place between 10:00 A.M. and 2:00 P.M. Animals were injected intraperitoneally with appropriate treatments, and $20 \mathrm{~min}$ later, they were placed into the center of a Plexiglas cage $(28 \times 18 \times 15 \mathrm{~cm})$ for $30 \mathrm{~min}$, during which they were videotaped at close range by a video camcorder positioned directly above the cage. The administered doses have been shown previously to induce different behavioral responses in both mice (Winslow and Miczek, 1983; Gingrich et al., 1999) and rats (West et al., 2000). Videotapes were scored for head twitches by an experienced observer blind to genotype and treatment. The experiment was conducted under dim light conditions (one $70 \mathrm{~W}$ light bulb illuminating the room facing away from the animals). Testing cages were thoroughly cleaned after each animal was tested to eliminate odor cues. The differences between the head-twitch response elicited by vehicle, DOI, LSD, and LHM in wild-type or 5-HT2AR null-mutant mice were assessed by Dunnett's post hoc test of one-way ANOVA of the normalized (square root) number of events.

Mouse somatosensory cortex sample processing. Experiments were performed on adult (8-12 weeks old) male 129Sv mice. Animals were housed individually in a $12 \mathrm{hr}$ light/dark cycle at room temperature $\left(22^{\circ} \mathrm{C}\right)$ with food and water available ad libitum. Animals were injected intraperitoneally with saline 1 week before the experiment to reduce the effect of stress of a novel stimulus on gene expression. The day of the experiment, drugs (DOI, LSD, or LHM) or vehicle was administrated intraperitoneally, and after the indicated time, the mice were killed by cervical dislocation and then decapitated. The brains were removed and washed in dry ice-cold RNase-free saline for 1-2 min. The two bilateral SSCx were dissected, frozen in dry ice, and stored at $-80^{\circ} \mathrm{C}$ until processing for total RNA isolation (Yuen et al., 2002b). The approximate yield was $30 \mu \mathrm{g}$ per mouse SSCx. For in situ hybridization assays, brains were removed and washed as described above and stored at $-80^{\circ} \mathrm{C}$ until use. All of the experiments took place between 10:00 A.M. and 2:00 P.M.

cDNA microarray development, probe labeling, and hybridization. The design, quality control, validation, and detailed protocols for use and analysis of this microarray have been described previously (Wurmbach et al., 2001, 2002). Total RNA (15-20 $\mu \mathrm{g}$ ) from each mouse SSCx (DOI and vehicle-treated) was labeled, and seven independent hybridizations from seven different DOI- or vehicle-treated mouse pairs were performed. cDNA array genes were identified as regulated on the basis of an algo- 
rithm described previously (Wurmbach et al., 2001). Briefly, genes selected for qRT-PCR confirmation presented a fold change of $>1.3,|t|$ statistics of $>3$, and signal intensity of $>1 \%$ of the median signal intensity in at least one channel.

Quantitative real-time PCR. We used a protocol with minor modifications that has been described previously (Yuen et al., 2002a). Each transcript in each sample was assayed four times, and the median threshold cycle $\left(C_{\mathrm{T}}\right)$ was used to calculate the fold change values [fold change ratios between experimental and control samples for each gene (FC)]. Data validity by modeling of reaction efficiency and analysis of measurement precision has been described previously (Yuen et al., 2002b).

In qRT-PCR experiments performed in mouse SSCx samples, four genes were used as internal controls for normalization ( $\beta$-actin, gapdh, ribosomal protein 33 , and mapkapk-5). The corrected $C_{\mathrm{T}}\left(c C_{\mathrm{T}}\right)$ for a given gene was calculated from the deviation of the $C_{\mathrm{T}}$ value obtained for each internal control gene in each sample from the overall average $C_{\mathrm{T}}$ for that internal control gene. Each normalization gene was assayed in quadruplicate in each sample, and the median $C_{\mathrm{T}}$ value was obtained in each sample used for analysis. Let the $C_{\mathrm{T}}$ value for each normalization gene in sample $i$ be represented by $n_{\mathrm{a} i}, n_{\mathrm{b} i}, n_{\mathrm{c} i}$, and $n_{\mathrm{d} i}$. Let $N_{\mathrm{a}}, N_{\mathrm{b}}, N_{\mathrm{c}}$, and $N_{\mathrm{d}}$ represent the median $C_{\mathrm{T}}$ values obtained for each normalization gene in all samples in that experiment. The correction factor $\theta_{i}$ for each sample $i$ was calculated as $\theta_{i}=\operatorname{median}\left(n_{\mathrm{a} i}-N_{\mathrm{a}}, n_{\mathrm{b} i}-N_{\mathrm{b}}, n_{\mathrm{c} i}-N_{\mathrm{c}}, n_{\mathrm{d} i}-\mathrm{N}_{\mathrm{d}}\right)$.

The $c C_{\mathrm{T}}$ for gene $\mathrm{X}$ (e.g., $c$-fos) could then be determined as $c C_{\mathrm{T}(c-f o s)}=$ $C_{\mathrm{T}(c-f o s)}-\theta$.

To determine the $\mathrm{FC}$ for given gene $\mathrm{X}$ in a drug-treated mouse, the mean of $2^{\text {cCT }}$ for that gene in cortex from all vehicle-treated animals (vehicle mean) was determined first. The fold change for each gene in each drug- or vehicle-treated animal (FC) was then calculated from the $c C_{\mathrm{T}}$ for that gene in that animal: $\mathrm{FC}=2^{\mathrm{cCT}} /$ vehicle mean.

Statistical differences between the $\log (\mathrm{FC})$ values in each group were assessed. When the effect of DOI, LSD, and LHM on the mRNA levels of the assayed genes was studied, the $\alpha$ value was corrected for multiple independent null hypotheses by using the Holm's sequentially rejective Bonferroni method as follows (Shaffer, 1995): $\alpha^{\prime}=1-(1-\alpha)^{(1 / N)}$, where $\alpha=0.05$ and $N=$ the number of independent null hypotheses ( 13 modulated genes presented in Table 1). Therefore, Student's $t$ test was considered significant at $p<0.0038$.

In situ hybridizations. Using subcloned and sequenced PCR fragments of the mouse $c$-fos [nucleotide (nt) 1780-2113] and the egr-1 (nt 397741) cDNA, high specific-activity RNA probes were produced from 200 ng of linearized plasmid using $\left[{ }^{35} \mathrm{~S}\right] \mathrm{UTP}(>1000 \mathrm{Ci} / \mathrm{mmol})$ (DuPont NEN, Boston, MA) and T3 or T7 RNA polymerase. Probes were purified on Micro Bio-Spin 6 chromatography columns (Bio-Rad, Hercules, CA). Cryostat sections $(10 \mu \mathrm{m})$ were postfixed in cold $4 \%$ paraformaldehyde, $1 \times$ PBS for $10 \mathrm{~min}$ at room temperature and rinsed twice in $1 \times$ PBS. Sections were incubated in $0.25 \%$ acetic anhydride, $0.1 \mathrm{~m}$ triethanolamine for $10 \mathrm{~min}$ at room temperature. After dehydration, the sections were hybridized overnight at $55^{\circ} \mathrm{C}$ with the labeled probe $\left(\sim 10^{6} \mathrm{dpm}\right)$ in $75 \mu \mathrm{l}$ of hybridization solution (100 mm Tris-HCl, 2 mм EDTA, $0.6 \mathrm{M}$ $\mathrm{NaCl}, 50 \%$ formamide, $10 \%$ dextran sulfate, $1 \times$ Denhardt's solution, $250 \mu \mathrm{g} / \mathrm{ml}$ yeast tRNA, and $50 \mu \mathrm{g} / \mathrm{ml}$ salmon sperm DNA, pH 8.0). After $60 \mathrm{~min}$ of RNase A $(10 \mu \mathrm{g} / \mathrm{ml})$ incubation at $37^{\circ} \mathrm{C}$, the sections were washed with $2 \times$ SSC ( $20 \mathrm{~min}$ at room temperature), $0.5 \times$ SSC, and $0.2 \times$ SSC $\left(30 \mathrm{~min}\right.$ at $\left.55^{\circ} \mathrm{C}\right)$. After dehydration, the sections were dried and exposed to Biomax MR films (Eastman Kodak, Rochester, NY) for 5-14 d. The autoradiograms were analyzed using the NIH Image program, version 1.62. Optical density values of SSCx from each mouse were averaged over at least two bilateral readings and subsequently converted to nanocuries per milligram of tissue equivalent with reference to $\left[{ }^{14} \mathrm{C}\right]$ standards. Differences between the measurements in DOI- and vehicletreated SSCx were assessed by unpaired Student's $t$ test.

\section{Results}

We first evaluated the feasibility of using gene responses to monitor cell signaling in 198A2 cells. Microarray studies allow the screening of a large number of candidates for differential levels of expression but are less accurate than high throughput qRT-PCR in determining the relative levels of expression observed (Yuen et al., 2002b). To provide global expression data at the level of accuracy required to profile the pattern of signaling, we used microarrays for screening and performed detailed studies using qRT-PCR assays. Studying 25,000 clusters by oligonucleotide microarrays (oligonucleotide microarrays data have been submitted to Gene Expression Omnibus, http://www.ncbi.nlm.nih.gov/ geo) and confirming candidates by specific qRT-PCR assays, we identified 23 transcripts for which expression levels were regulated in 198A2 cells after exposure to $10^{-5}$ M 5 -HT for $1 \mathrm{hr}$ (supplementary Tables 1 and 2; available at www.jneurosci.org). We studied whether transcripts showing the largest induction with 5-HT were differentially activated by structurally distinct 5-HT2AR agonists. Concentration-response curves for gene induction by four agonists in 198A2 cells showed that these agonists differed in their relative capacity to activate different genes (Fig. $1 A$ ) and that the global gene response profile obtained was specific for each agonist studied (Fig. $1 B$ ). The agonists that were tested caused no changes in expression of the genes studied in the parent HEK293 cell line, which does not express the 5-HT2AR (data not shown). These results suggest that these agonists, when complexed with the 5-HT2AR, induced different patterns of cellular signaling that were translated into the unique transcriptome fingerprints (TFPs) that were observed.

We investigated whether TFPs in mouse cortex could discriminate among partial agonists for the 5-HT2ARs that differ in behavioral activity in vivo (Fig. $2 \mathrm{~A}$ ). We first assayed the rodent head-twitch response, which is strongly correlated with 5-HT2AR activation (Willins and Meltzer, 1997; Gewirtz and Marek, 2000). We found that the ligands LSD and DOI activated a significant head-twitch response in mice (Fig. $2 B$ ). In contrast, LHM, which is closely related both chemically (Fig. 2A) and pharmacologically (Egan et al., 1998; Porter et al., 1999) to LSD, failed to induce this behavioral response. We investigated the role of the 5-HT2AR in mediating the head-twitch response by studying the effects of these agonists in 5-HT2AR null-mutant mice. No significant response was observed in mutant mice for any of these agonists (Fig. 2B). The expression level of 30 other neurotransmitter receptor transcripts, as well as cortical cytoarchitecture, is comparable in wild-type and 5-HT2AR null-mutant mice (Gingrich et al., 1999). Therefore, the absent behavioral responses in the mutant animals resulted solely from the loss of the 5-HT2AR, additionally supporting the essential role of this specific molecular target in mediating the psychotropic effects of these drugs.

We then studied agonist modulation of gene expression in SSCx, a region implicated in the neuropsychological activity of 5-HT2AR agonists (Jakab and Goldman-Rakic, 1998; Scruggs et al., 2000). Candidate transcripts to study by qRT-PCR assays were selected from those identified in mouse cortex cDNA microarray experiments or from the 198A2 cell line microarray studies described above. DOI was selected for in vivo microarray experiments because of its unique structure and its robust stimulation of 5-HT2AR-dependent behavioral responses (Fig. 2). Seven microarray assays were performed with SSCx mRNA samples obtained from different mice $1 \mathrm{hr}$ after injection with either DOI or vehicle. We used a thresholding algorithm that has been reported previously (Wurmbach et al., 2001) to identify the genes regulated by DOI in mouse SSCx (cDNA microarrays data have been submitted to Gene Expression Omnibus, http://www. ncbi.nlm.nih.gov/geo). Significant regulation of candidate transcripts identified through microarray experiments was 


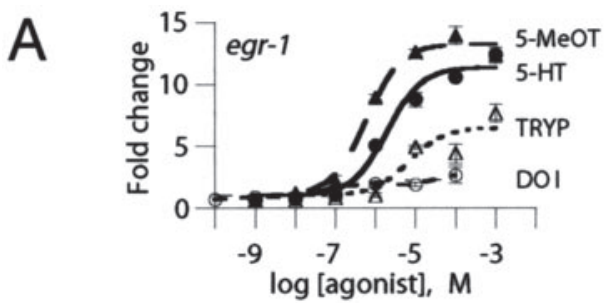

B

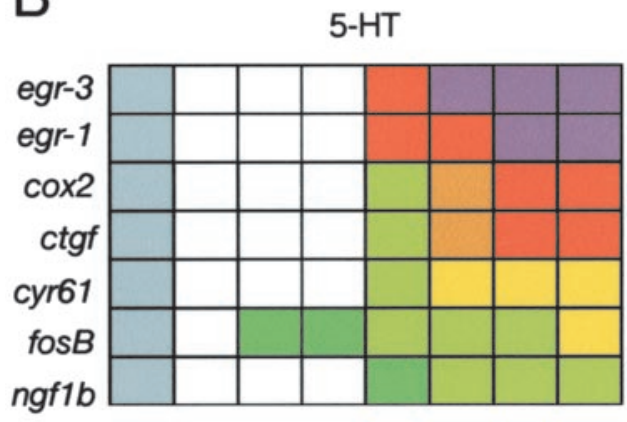

TRYP
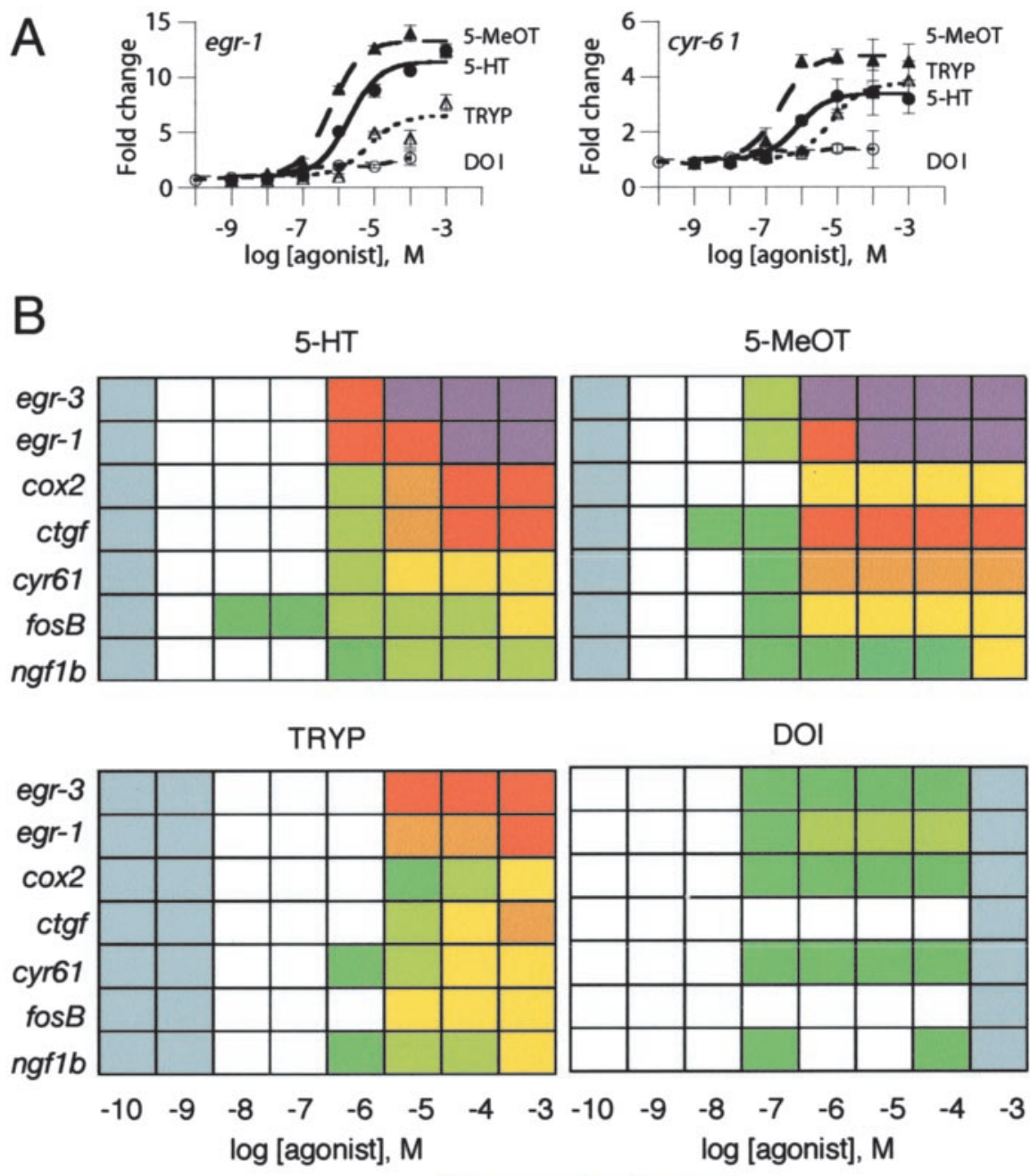

5-MeOT

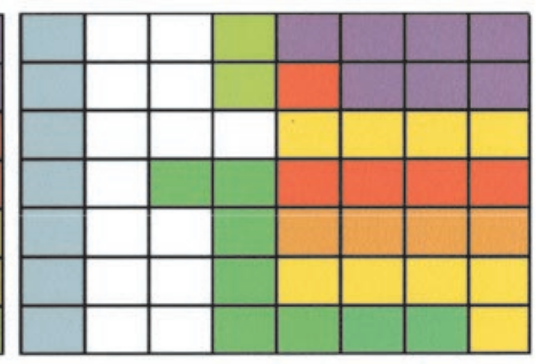

DOI

Figure 1. Quantitative transcriptional responses to 5-HT2AR agonists in $198 \mathrm{~A} 2$ cells. Fold changes are expressed relative to vehicle-treated samples. A, Concentration-response curves for 5-HT, 5-methoxy-tryptamine (5-Me0T), tryptamine (TRYP), and DOI inducing the expression of egr- 1 and cyr61. Data are means \pm SEM from three samples. $B$, TFPs showing the pattern of response obtained for seven modulated transcripts. Gray indicates that agonist was not tested at that concentration.

confirmed by qRT-PCR and, for selected transcripts, by in situ hybridization (Fig. 3).

To select the optimum time point for subsequent studies, the time courses of gene expression in SSCx after DOI exposure were investigated. Measurement variability was reduced by an aggregate normalization algorithm incorporating assays of four housekeeping genes (see Materials and Methods). Although the temporal pattern of induction by DOI varied for several transcripts (Fig. $3 B$ ), most genes showed maximal changes at $\sim 60$ min after DOI exposure, and this time point was selected for subsequent studies. We also found that both induced and suppressed transcripts showed dose-dependent responses, indicating that these transcripts provide an in vivo signaling assay with a measurement range useful for comparing different agonists (Fig. 3C).

We next quantified the effects on gene expression of the three agonists evaluated in the head-twitch study. Transcript levels $1 \mathrm{hr}$ after injection of each agonist were compared with results obtained in vehicle-injected control animals by qRT-PCR. Thirteen

3

\section{Discussion}

To understand the mechanisms underlying differences in the behavioral effects elicited by various 5-HT2AR agonists, we measured the changes in gene expression induced in vitro and in vivo. This application of high throughput quantitative genomics provides a detailed and specific portrait of the global signaling responses induced by activation of a heptahelical receptor. We demonstrate that specific TFPs are obtained after exposure to 5-HT2AR agonists, providing the basis for correlating genomic-based signal transduction and behavioral pharmacology in vivo.

transcripts showed significant changes inand 6 transcripts regulated by DOI, ISD, and LHM, respectively (Table 1, Fig. 4) (see also supplementary Table 3 ). Each agducible TFP. Three genes, $c$-fos, N-10, and $I-\kappa B \alpha$, showed a similar modulation by all egr-2, and period-1 were unaffected by LHM, which caused no head-twitch restructurally dissimilar agonists DOI and LSD, which were active in the behavioral . The agonists that were assayed comthe 5-HT2AR (Nichols, 1997). Therefore, we generated TFPs in the 5-HT2AR nullin gene expression required expression of cexpresion and LSD and LHM altered the expression of only a single transcript, $I-\kappa B \alpha$ (Table 1 , Fig. 4). These data demonstrate that the in the absence of 5-HT2AR activation are detected by this assay and that modulation of nearly all transcripts that were obtained depends on 5-HT2AR expression. Our data support the hypothesis that agonists acting at the
me molecular receptor in vivo can induce unique patterns of same molecular receptor in vivo can induce unique patterns of
signaling, thereby eliciting different behavioral responses. We find that the TFPs obtained in SSCx with each agonist are unique and dependent nearly entirely on expression of the 5-HT2AR, as shown by their absence in 5-HT2AR null-mutant mice. Although we cannot exclude the possibility that the unique patterns of response result from simultaneous activation of receptor subtypes other than the 5-HT2AR, the demonstration that different agonists also can generate unique TFPs in the 5-HT2ARexpressing cell line makes this more complicated explanation for differences in drug effects less likely.

The agonist-specific TFPs observed may result from their pharmacophore and pharmacokinetic profiles. LHM has been reported to elicit behavioral responses in rodents, which although it is not believed to occur via 5-HT2AR activation (MaronaLewicka et al., 2002), it does provide a means for comparison of 
A<smiles>CCC(C)C(C)C(C)C</smiles>

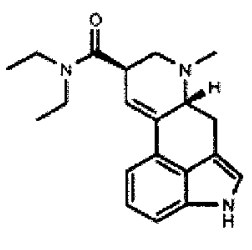

LSD

B

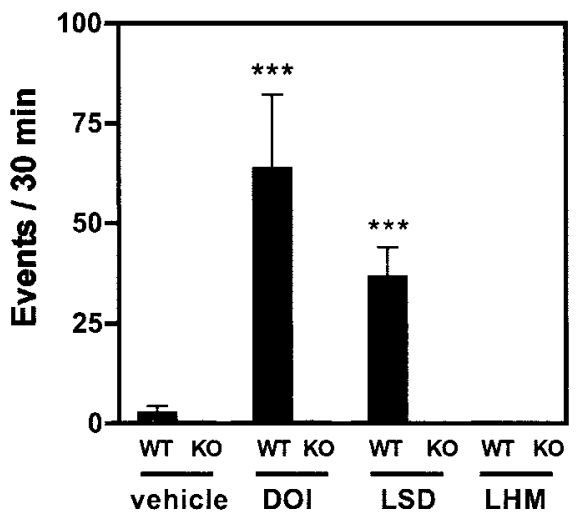

Figure 2. Behavioral responses to 5-HT2AR agonists. A, Chemical structure of the 5-HT2AR partial agonists studied in vivo. $B$, Wild-type (WT) and 5-HT2AR null-mutant (KO) mice ( $n=6$ per treatment group) were injected with vehicle DOI ( $2 \mathrm{mg} / \mathrm{kg}$, i.p.), LSD $(0.24 \mathrm{mg} / \mathrm{kg}$, i.p.), or LHM $(0.4 \mathrm{mg} / \mathrm{kg}$, i.p.), and the head-twitch response was scored $20 \mathrm{~min}$ after injection for 30 $\min .{ }^{* * *} p<0.001$; Dunnett's post hoc test of one-way ANOVA of the normalized events.

the pharmacokinetics of LHM, LSD, and DOI. The onset and peak behavioral responses to DOI, LSD, and LHM after intraperitoneal administration in rodents are similar (Mokler and Rech, 1984; Gewirtz and Marek, 2000). The comparable pharmacokinetics of LSD and LHM are also supported by nearly identical dose-response curves obtained with intracerebroventricular and intraperitoneal administration of each agonist (Mokler and Rech, 1984). Also pertinent specifically to the assay of gene changes after receptor activation are studies in cell lines suggesting that only the amplitude but not the pattern of gene induction over time depends on the intensity of the inducing stimulus (Yuen et al., 2002c). These considerations suggest that the differences in the identities of the genes modulated by each agonist are unlikely to result from differences in absorption and kinetics. We find that DOI and LSD elicit a marked 5-HT2AR-dependent increase in the head-twitch response, whereas LHM causes no change in this behavior (Fig. 2). Notably, the TFP data indicate that the absence of behavioral responses does not result simply because LHM is a weaker partial agonist at the 5-HT2AR. Indeed, some components of the TFP, such as jun-B and sty kinase, show a larger stimulation by LHM than by the two behaviorally active agonists (Fig. 4). Therefore, the unique behavioral and signaling responses elicited by each agonist studied in vivo appear to result from agonist-specific differences in the activation of multiple signaling pathways coupled to the 5-HT2AR.

The induction of the transcription factor Fos has been used previously to study 5-HT2AR activation and the mechanism of action of hallucinogens in rodent cortex (Scruggs et al., 2000; Gresch et al., 2002). In the present study, we found that all three 5-HT2AR agonists induced the transcription of $c$-fos in mouse SSCX in a 5-HT2AR-dependent manner. Notably, only the two

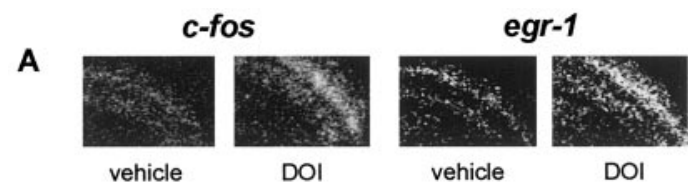

B

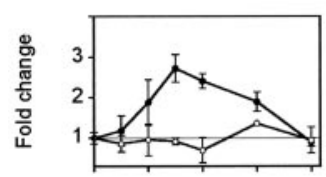

C
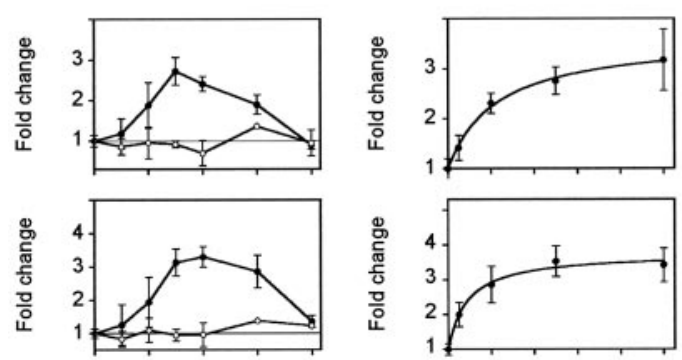

c-fos
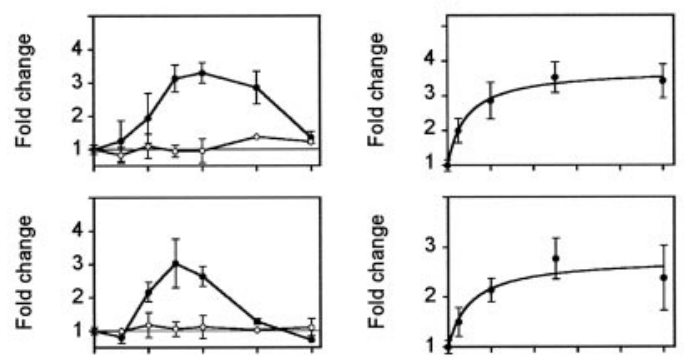

egr-2
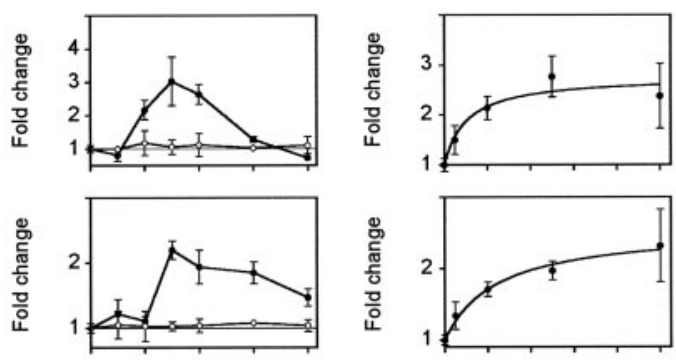

N-10
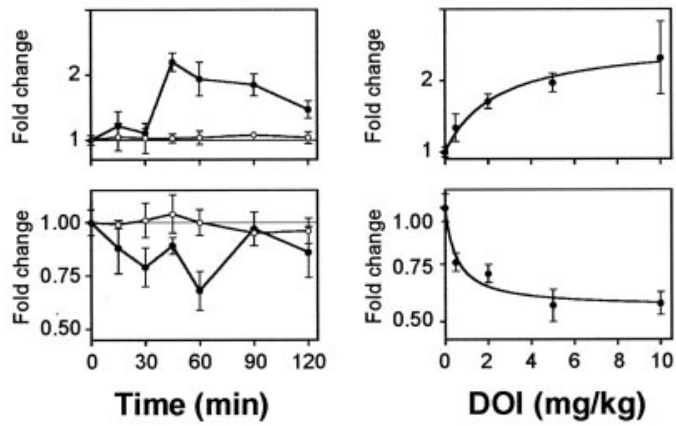

$I-\kappa B \alpha$

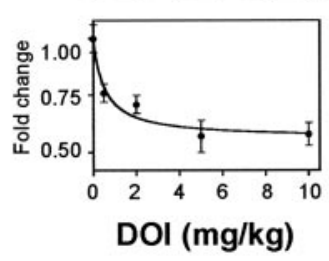

sty kinase

Figure 3. Characterization of the gene expression changes induced by DOl in mouse SSCX.A, Autoradiographs of coronal brain sections from mice injected with vehicle $(n=4)$ or DOI (8 $\mathrm{mg} / \mathrm{kg}$, i.p.; $n=8$ ), killed after $60 \mathrm{~min}$, and hybridized with cRNAs for $(-$ fos or egr-1. DOI significantly increased the level of expression of genes assayed in $\operatorname{SSCX}(p<0.05)$. B, Time courses of the DOI-induced gene response assayed by qRT-PCR. Mice were injected with DOI ( 2 $\mathrm{mg} / \mathrm{kg}$, i.p.; filled symbols; $n=4-8$ ) or vehicle ( $n=2-4$; open symbols) and killed at the times indicated. Results represent mean \pm SEM of the fold changes compared with basal levels of expression. C, Dose-response curves of the DOl-induced gene response assayed by qRT-PCR. Mice were injected intraperitoneally with the doses of DOl indicated $(n=6)$ and killed after 60 $\mathrm{min}$. Data expressed are means \pm SEM of the fold changes in comparison with levels of expression in vehicle-injected mice.

hallucinogens, DOI and LSD, induced increased expression of egr-1, egr-2, and period-1 transcripts. Our results indicate that the use of induction of an early gene, such as $c$-fos, as a marker of neuronal activity can be interpreted more reliably in context of the overall changes in gene expression. Thus, in this experimental paradigm, our data suggest that $c$-fos is a nonspecific marker of agonist activation of the 5-HT2AR. In contrast, the genes for egr-1, egr-2, and period-1 are activated by changes in cortical signaling that appear to be specific effects of the two hallucinogenic agonists and that correlate with the generation of a head-twitch behavioral response.

The 198A2 cell studies were undertaken to demonstrate that gene responses could be used to generate concentration-response curves comparable with classical pharmacological assays and that the TFPs generated could distinguish the effects of different agonists acting at the same receptor; however, although both the in vitro and in vivo studies focused on 5-HT2AR agonist activities, the overall signal transduction amplification systems 
Table 1. Fold changes of the gene transcripts in drug- compared with vehicle-treated wild-type (WT) and 5-HT2AR null-mutant (K0) mice estimated by qRT-PCR by using an aggregate normalization algorithm incorporating assays of four housekeeping genes

\begin{tabular}{|c|c|c|c|c|c|c|}
\hline \multirow[b]{2}{*}{ Gene name } & \multicolumn{3}{|l|}{ WT } & \multicolumn{3}{|l|}{ 5-HT2AR-KO } \\
\hline & DOl & LSD & LHM & DOl & LSD & LHM \\
\hline egr-1 & $11.30 \pm 2.72^{*}$ & $4.34 \pm 1.20^{*}$ & $0.95 \pm 0.05$ & $0.98 \pm 0.31$ & $1.01 \pm 0.08$ & $1.04 \pm 0.23$ \\
\hline$c-f o s$ & $2.31 \pm 0.18^{*}$ & $2.11 \pm 0.15^{*}$ & $1.48 \pm 0.10^{*}$ & $1.09 \pm 0.12$ & $1.08 \pm 0.09$ & $1.10 \pm 0.03$ \\
\hline$N-10$ & $2.10 \pm 0.42^{*}$ & $1.70 \pm 0.16^{*}$ & $1.45 \pm 0.12^{* *}$ & $0.93 \pm 0.13$ & $1.00 \pm 0.08$ & $1.07 \pm 0.08$ \\
\hline $1-k B a$ & $1.58 \pm 0.08^{*}$ & $1.35 \pm 0.09^{*}$ & $1.67 \pm 0.06^{*}$ & $1.02 \pm 0.08$ & $1.40 \pm 0.13^{*}$ & $1.80 \pm 0.21^{*}$ \\
\hline$A R 1$ & $1.46 \pm 0.05^{*}$ & $1.11 \pm 0.14$ & $0.71 \pm 0.04^{* *}$ & $0.95 \pm 0.07$ & $1.08 \pm 0.04$ & $1.08 \pm 0.13$ \\
\hline erk1 & $1.10 \pm 0.15$ & $0.98 \pm 0.04$ & $0.98 \pm 0.05$ & $1.02 \pm 0.10$ & $1.02 \pm 0.11$ & $0.97 \pm 0.09$ \\
\hline Fra1 & $1.05 \pm 0.09$ & $1.00 \pm 0.07$ & $1.09 \pm 0.09$ & $0.93 \pm 0.13$ & $1.04 \pm 0.13$ & $0.94 \pm 0.09$ \\
\hline jun $-B$ & $1.04 \pm 0.08$ & $1.58 \pm 0.10^{*}$ & $1.61 \pm 0.11^{*}$ & $0.97 \pm 0.07$ & $1.07 \pm 0.07$ & $1.01 \pm 0.05$ \\
\hline synapsin1b & $1.03 \pm 0.05$ & $0.99 \pm 0.06$ & $1.06 \pm 0.06$ & $1.04 \pm 0.03$ & $1.08 \pm 0.03$ & $0.92 \pm 0.13$ \\
\hline Glut4 & $1.01 \pm 0.14$ & $0.79 \pm 0.07^{* *}$ & $1.06 \pm 0.05$ & $0.95 \pm 0.13$ & $1.05 \pm 0.07$ & $0.94 \pm 0.05$ \\
\hline ets1 & $0.99 \pm 0.04$ & $1.03 \pm 0.05$ & $0.97 \pm 0.02$ & $0.94 \pm 0.12$ & $1.01 \pm 0.10$ & $1.05 \pm 0.06$ \\
\hline egr-3 & $0.74 \pm 0.07^{*}$ & $1.07 \pm 0.08$ & $0.93 \pm 0.06$ & $0.96 \pm 0.06$ & $1.01 \pm 0.03$ & $0.93 \pm 0.05$ \\
\hline
\end{tabular}

Statistical significance was assessed by Student's $t$ test of the normalized (log) fold changes. The $\alpha$ value was corrected for multiple independent null hypotheses by using the "Holm's" sequentially rejective Bonferroni method. Therefore, the level of significance was chosen at $p=0.0038 .{ }^{*} p<0.001 ;{ }^{* *} p<0.0038$ (see qRT-PCR data analysis). See supplementary Table 3 (available at www.jneurosci.org) for GenBank accession numbers and primer sequences.

present in 198A2 cells and in mouse SSCx and the levels of receptor expressed per cell may differ, and therefore the in vitro feasibility studies should not be compared directly with the in vivo TFP assays. Not all agonists with activity in vivo show responses in this stable cell line. Although LSD and LHM have considerable activity in vivo (Table 1, Fig. 4), their signaling activity using both conventional phosphatidylinositol hydrolysis and TFP are at the lower limits of reproducible assay (Ebersole et al., 2003) (data not shown).

TFPs monitor changes in signaling that correlate with the behavioral response that are assayed; however, the changes in transcript expression and the behavioral response occur contemporaneously and are unlikely to be causally related. In this respect, the TFPs can be thought of as conceptually similar to genetic biosensors or signaling reporters that have been introduced into transgenic models (Impey et al., 1996). Unlike reporter constructs, however, TFPs do represent actual modulation of gene programs in mouse SSCX and therefore provide insight into the specific modulation of biosynthetic programs by each agonist. For example, the transcript of the adenosine A1 receptor (arl) was found to be induced by DOI, unchanged by LSD, and downregulated by LHM. The adenosine A1 receptor opposes the activating effects of 5-HT2AR stimulation in the rodent cortex (Stutzmann et al., 2001). Thus, the differential regulation observed could result in drug-specific enhancement or suppression of the responses to subsequent 5-HT2AR activation.

An intriguing relationship exists between the modulation of affect, attention, and cognition by hallucinogenic drugs that activate 5-HT2ARs and the antipsychotic activity of "atypical" neuroleptic drugs, such as clozapine, which are 5-HT2AR antagonists. We found that the transcription of period-1, a circadian rhythm-related gene (Cermakian et al., 2001), was selectively regulated by the hallucinogens DOI and LSD but not by LHM. Interestingly, clozapine, unlike classic neuroleptics, has been reported to regularize circadian rhythms in patients with schizophrenia (Wirz-Justice et al., 2001). We also found that the nuclear receptor $\mathrm{N}-10$ transcript was induced by all of the 5-HT2AR agonists studied in vivo. Consistent with our finding, this transcription factor has been reported to be downregulated in the rat forebrain after both acute and chronic clozapine exposure (Langlois et al., 2001).

The responses assayed using TFPs represent signal processing that occurs both intracellularly and via intercellular circuits. The cellular and electrophysiological responses elicited by hallucinogenic drugs of abuse have been investigated by several laboratories (Aghajanian and Marek, 2000; Scruggs et al., 2000; Lambe and Aghajanian, 2001; Martin-Ruiz et al., 2001; Gewirtz et al., 2002). Studies suggest that hallucinogenic drugs increase glutamate release by acting predominantly on presynaptic 5-HT2ARs located on thalamocortical terminals in neocortex (Aghajanian and Marek, 2000; Marek et al., 2001). Local application of DOI in medial prefrontal cortex induces a head-twitch behavioral response in rats (Willins and Meltzer, 1997), and the activation of 5-HT2ARs located on thalamic afferents have also been suggested to mediate this effect (Gewirtz and Marek, 2000). The localization of the DOI-induced upregulation of $c$-fos and egr-1 mRNA that we observed agrees with previous studies reporting gene induction in rodent neocortex by 5-HT2AR agonists (Vaidya et al., 1997; Scruggs et al., 2000) and is similar to the distribution of the 5-HT2AR, which is concentrated in layers II/III and V/VI (LopezGimenez et al., 1997; Jakab and Goldman-Rakic, 1998).

The pyramidal neurons constitute the major 5-HT2ARexpressing cells in the neocortex (Jakab and Goldman-Rakic, 1998). Therefore, the proposed preferential action of hallucinogenic agonists on 5-HT2ARs located on thalamocortical terminals would leave the dense population of pyramidal 5-HT2ARs without a significant role in the effects of these drugs on the cortex; however, previous work in SSCx has relied on induction of $c$-fos, which our data suggest reflects a change in cortical cells that is less specific for neuroactive chemicals than that represented by the induction of other early genes, such as egr-1. The differences in cortical signal processing resulting from general 5-HT2AR activation (e.g., induction of $c$-fos) and from behaviorally active agonists (e.g., induction of egr-1) provide the basis for studies at a cellular level of resolution to clarify which neurons and cortical circuits mediate these responses. 


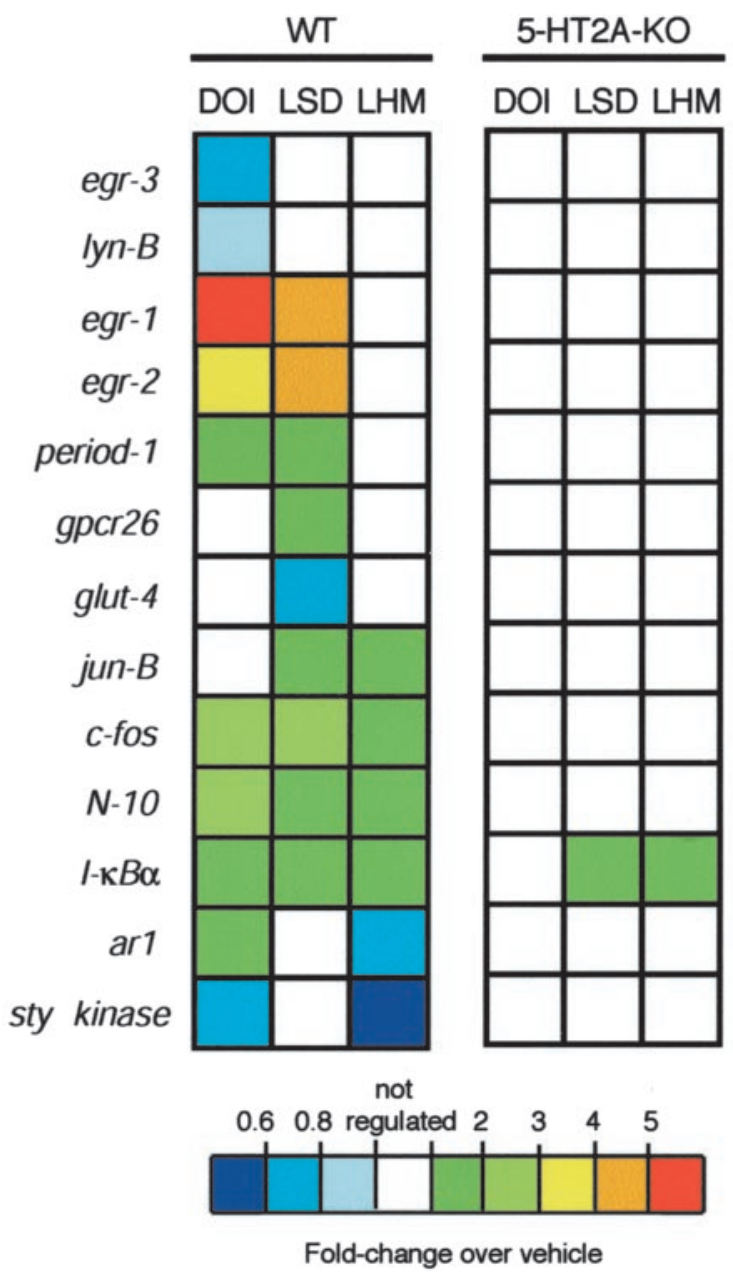

Figure 4. TFPs induced by 5-HT2AR agonists in SSCx from wild-type (WT) and 5-HT2AR null-mutant (KO) mice determined by qRT-PCR assays. Mice were injected intraperitoneally with vehicle (WT, $n=12 ; \mathrm{KO}, n=6)$, DOI ( $2 \mathrm{mg} / \mathrm{kg} ; \mathrm{WT} ; n=21 ; \mathrm{KO}, n=6), \mathrm{LSD}(0.24 \mathrm{mg} / \mathrm{kg}$; $\mathrm{WT}, n=12 ; \mathrm{KO}, n=6)$, or LHM ( $(0.4 \mathrm{mg} / \mathrm{kg} ; \mathrm{WT} ; n=12 ; \mathrm{K} 0, n=6)$ and killed after $60 \mathrm{~min}$. Relative fold changes in levels of mRNA expression of 13 transcripts are shown. The basal expression levels of all of the assayed transcripts were comparable in WT and K0 mice (data not shown) (Table 1). See also supplementary Table 3.

A single receptor subtype may affect multiple interconnected signaling pathways (Jordan et al., 2000), and specific agonists acting at the same receptor differ in their relative activation of these different signaling pathways (Kenakin, 1995). For example, agonists acting at the 5-HT2AR in cell lines have been shown to differ in their relative activation of phosphoinositol and arachidonic acid signaling pathways (Berg et al., 1998). In addition, distinct electrophysiological responses involving 5-HT2AR activation by different agonists have been reported in cortical pyramidal neurons (Aghajanian and Marek, 1999b; Arvanov et al., 1999). Recent studies suggest that heptahelical receptors assume distributions among multiple active and inactive conformers (Peleg et al., 2001; Prioleau et al., 2002). Agonists achieve their physiological effects by complexing with the receptors and altering the relative distribution of these conformers. Computational simulations with a receptor model (Zhang and Weinstein, 1993) and autoradiographic binding experiments in the human cortex (Lopez-Gimenez et al., 2001) are also consistent with the existence of ligand-selective 5-HT2AR conformational states. Our approach provides a means for quantifying the global changes in signaling that occur after receptor activation, and our data support the existence of agonist-mediated signal trafficking in vivo.

We demonstrate that the 5-HT2AR discriminates between different activating drugs as reflected in both behavioral responses and the modulation of the regional brain transcriptome. The signal processing that occurs after agonist activation of the 5-HT2AR, either at the level of the single cells or at the level of neuronal circuits, leads to distinct drug-specific patterns of response that are reflected in the unique TFPs obtained. The use of quantitative genomics to assay the effects of drug-receptor interactions in complex systems provides a new tool to elucidate the signal-transduction effects of different drugs acting at the same molecular target in the brain and may provide the basis for rational design of signaling pathway-specific neuropharmacological drugs.

\section{References}

Aghajanian GK, Marek GJ (1999a) Serotonin and hallucinogens. Neuropsychopharmacology 21:16S-23S.

Aghajanian GK, Marek GJ (1999b) Serotonin, via 5- $\mathrm{HT}_{2 \mathrm{~A}}$ receptors, increases EPSCs in layer $\mathrm{V}$ pyramidal cells of prefrontal cortex by an asynchronous mode of glutamate release. Brain Res 825:161-171.

Aghajanian GK, Marek GJ (2000) Serotonin model of schizophrenia: emerging role of glutamate mechanisms. Brain Res Brain Res Rev 31:302-312.

Arvanov VL, Liang X, Russo A, Wang RY (1999) LSD and DOB: interaction with $5-\mathrm{HT}_{2 \mathrm{~A}}$ receptors to inhibit NMDA receptor-mediated transmission in the rat prefrontal cortex. Eur J Neurosci 11:3064-3072.

Barnes NM, Sharp T (1999) A review of central 5-HT receptors and their function. Neuropharmacology 38:1083-1152.

Berg KA, Maayani S, Goldfarb J, Scaramellini C, Leff P, Clarke WP (1998) Effector pathway-dependent relative efficacy at serotonin type $2 \mathrm{~A}$ and $2 \mathrm{C}$ receptors: evidence for agonist-directed trafficking of receptor stimulus. Mol Pharmacol 54:94-104.

Cermakian N, Monaco L, Pando MP, Dierich A, Sassone-Corsi P (2001) Altered behavioral rhythms and clock gene expression in mice with a targeted mutation in the Period1 gene. EMBO J 20:3967-3974.

Clayton DF (2000) The genomic action potential. Neurobiol Learn Mem 74:185-216.

Cordeaux Y, Nickolls SA, Flood LA, Graber SG, Strange PG (2001) Agonist regulation of $\mathrm{D}_{2}$ dopamine receptor/G-protein interaction. Evidence for agonist selection of G-protein subtype. J Biol Chem 276:28667-28675.

Cussac D, Newman-Tancredi A, Duqueyroix D, Pasteau V, Millan MJ (2002) Differential activation of $\mathrm{Gq} / 11$ and $\mathrm{Gi}_{3}$ proteins at 5-hydroxytryptamine $_{2 \mathrm{C}}$ receptors revealed by antibody capture assays: influence of receptor reserve and relationship to agonist-directed trafficking. Mol Pharmacol 62:578-589.

Ebersole BJ, Visiers I, Weinstein H, Sealfon SC (2003) Molecular basis of partial agonism: orientation of indoleamine ligands in the binding pocket of the human serotonin $5-\mathrm{HT}_{2 \mathrm{~A}}$ receptor determines relative efficacy. Mol Pharmacol 63:36-43.

Egan CT, Herrick-Davis K, Miller K, Glennon RA, Teitler M (1998) Agonist activity of LSD and lisuride at cloned $5 \mathrm{HT}_{2 \mathrm{~A}}$ and $5 \mathrm{HT}_{2 \mathrm{C}}$ receptors. Psychopharmacology (Berl) 136:409-414.

Fiorella D, Rabin RA, Winter JC (1995) The role of the 5- $\mathrm{HT}_{2 \mathrm{~A}}$ and 5- $\mathrm{HT}_{2 \mathrm{C}}$ receptors in the stimulus effects of hallucinogenic drugs. I: Antagonist correlation analysis. Psychopharmacology (Berl) 121:347-356.

Gewirtz JC, Marek GJ (2000) Behavioral evidence for interactions between a hallucinogenic drug and group II metabotropic glutamate receptors. Neuropsychopharmacology 23:569-576.

Gewirtz JC, Chen AC, Terwilliger R, Duman RC, Marek GJ (2002) Modulation of DOI-induced increases in cortical BDNF expression by group II mGlu receptors. Pharmacol Biochem Behav 73:317-326.

Gingrich JA, Zhou M, Sealfon SC, Hen R (1999) Mice lacking 5- $\mathrm{HT}_{2 \mathrm{~A}}$ receptor are insensitive to many of the behavioral and physiological effects of hallucinogens. Soc Neurosci Abstr 25:799.

Gresch PJ, Strickland LV, Sanders-Bush E (2002) Lysergic acid diethylamide-induced Fos expression in rat brain: role of serotonin-2A receptors. Neuroscience 114:707-713. 
Hill SJ, Baker JG, Rees S (2001) Reporter-gene systems for the study of G-protein-coupled receptors. Curr Opin Pharmacol 1:526-532.

Impey S, Mark M, Villacres EC, Poser S, Chavkin C, Storm DR (1996) Induction of CRE-mediated gene expression by stimuli that generate longlasting LTP in area CA1 of the hippocampus. Neuron 16:973-982.

Jakab RL, Goldman-Rakic PS (1998) 5-Hydroxytryptamine2A serotonin receptors in the primate cerebral cortex: possible site of action of hallucinogenic and antipsychotic drugs in pyramidal cell apical dendrites. Proc Natl Acad Sci USA 95:735-740.

Jordan JD, Landau EM, Iyengar R (2000) Signaling networks: the origins of cellular multitasking. Cell 103:193-200.

Kenakin T (1995) Agonist-receptor efficacy. II. Agonist trafficking of receptor signals. Trends Pharmacol Sci 16:232-238.

Kenakin T (1997) Differences between natural and recombinant G-proteincoupled receptor systems with varying receptor/G-protein stoichiometry. Trends Pharmacol Sci 18:456-464.

Lambe EK, Aghajanian GK (2001) The role of Kv1.2-containing potassium channels in serotonin-induced glutamate release from thalamocortical terminals in rat frontal cortex. J Neurosci 21:9955-9963.

Langlois MC, Beaudry G, Zekki H, Rouillard C, Levesque D (2001) Impact of antipsychotic drug administration on the expression of nuclear receptors in the neocortex and striatum of the rat brain. Neuroscience 106:117-128.

Lopez-Gimenez JF, Mengod G, Palacios JM, Vilaro MT (1997) Selective visualization of rat brain 5-HT2A receptors by autoradiography with $\left[{ }^{3} \mathrm{H}\right] \mathrm{MDL} \quad 100,907$. Naunyn Schmiedebergs Arch Pharmacol 356:446-454.

Lopez-Gimenez JF, Villazon M, Brea J, Loza MI, Palacios JM, Mengod G, Vilaro MT (2001) Multiple conformations of native and recombinant human 5-hydroxytryptamine ${ }_{2 \mathrm{~A}}$ receptors are labeled by agonists and discriminated by antagonists. Mol Pharmacol 60:690-699.

Marek GJ, Wright RA, Gewirtz JC, Schoepp DD (2001) A major role for thalamocortical afferents in serotonergic hallucinogen receptor function in the rat neocortex. Neuroscience 105:379-392.

Marona-Lewicka D, Kurrasch-Orbaugh DM, Selken JR, Cumbay MG, Lisnicchia JG, Nichols DE (2002) Re-evaluation of lisuride pharmacology: 5-hydroxytryptamine1A receptor-mediated behavioral effects overlap its other properties in rats. Psychopharmacology (Berl) 164:93-107.

Martin-Ruiz R, Puig MV, Celada P, Shapiro DA, Roth BL, Mengod G, Artigas F (2001) Control of serotonergic function in medial prefrontal cortex by serotonin-2A receptors through a glutamate-dependent mechanism. J Neurosci 21:9856-9866.

Meltzer HY (1999) The role of serotonin in antipsychotic drug action. Neuropsychopharmacology 21:106S-115S.

Mokler DJ, Rech RH (1984) Behavioral effects of intracerebroventricular administration of LSD, DOM, mescaline or lisuride. Pharmacol Biochem Behav 21:281-287.

Nichols DE (1997) Role of serotoninergic neurons and 5-HT receptors in the action of hallucinogens. In: Serotoninergic neurons and 5-HT receptors in the CNS (Baumgarten HG, Gothert M, eds), pp 563-585. Berlin: Springer.

Peleg G, Ghanouni P, Kobilka BK, Zare RN (2001) Single-molecule spectroscopy of the $\beta_{2}$ adrenergic receptor: observation of conformational substates in a membrane protein. Proc Natl Acad Sci USA 98:8469-8474.

Pieri L, Keller HH, Burkard W, Da Prada M (1978) Effects of lisuride and LSD on cerebral monoamine systems and hallucinosis. Nature 272:278-280.
Porter RH, Benwell KR, Lamb H, Malcolm CS, Allen NH, Revell DF, Adams DR, Sheardown MJ (1999) Functional characterization of agonists at recombinant human $5-\mathrm{HT}_{2 \mathrm{~A}}, 5-\mathrm{HT}_{2 \mathrm{~B}}$ and $5-\mathrm{HT}_{2 \mathrm{C}}$ receptors in $\mathrm{CHO}-\mathrm{K} 1$ cells. Br J Pharmacol 128:13-20.

Prioleau C, Visiers I, Ebersole BJ, Weinstein H, Sealfon SC (2002) Conserved helix 7 tyrosine acts as a multistate conformational switch in the $5 \mathrm{HT}_{2 \mathrm{C}}$ receptor: identification of a novel "locked-on" phenotype and double revertant mutations. J Biol Chem 277:36577-36584.

Scruggs JL, Patel S, Bubser M, Deutch AY (2000) DOI-Induced activation of the cortex: dependence on $5-\mathrm{HT}_{2 \mathrm{~A}}$ heteroceptors on thalamocortical glutamatergic neurons. J Neurosci 20:8846-8852.

Shaffer JP (1995) Multiple hypothesis testing. Annu Rev Psychol 46:561-584.

Stutzmann GE, Marek GJ, Aghajanian GK (2001) Adenosine preferentially suppresses serotonin $_{2 \mathrm{~A}}$ receptor-enhanced excitatory postsynaptic currents in layer $\mathrm{V}$ neurons of the rat medial prefrontal cortex. Neuroscience 105:55-69.

Vaidya VA, Marek GJ, Aghajanian GK, Duman RS (1997) 5-HT2A receptor-mediated regulation of brain-derived neurotrophic factor mRNA in the hippocampus and the neocortex. J Neurosci 17:2785-2795.

Vollenweider FX, Vollenweider-Scherpenhuyzen MF, Babler A, Vogel H, Hell D (1998) Psilocybin induces schizophrenia-like psychosis in humans via a serotonin-2 agonist action. NeuroReport 9:3897-3902.

West WB, Lou A, Pechersky K, Chachich ME, Appel JB (2000) Antagonism of a PCP drug discrimination by hallucinogens and related drugs. Neuropsychopharmacology 22:618-625.

White FJ, Appel JB (1982) Lysergic acid diethylamide (LSD) and lisuride: differentiation of their neuropharmacological actions. Science 216:535-537.

Willins DL, Meltzer HY (1997) Direct injection of 5-HT2A receptor agonists into the medial prefrontal cortex produces a head-twitch response in rats. J Pharmacol Exp Ther 282:699-706.

Winslow JT, Miczek KA (1983) Habituation of aggression in mice: pharmacological evidence of catecholaminergic and serotonergic mediation. Psychopharmacology (Berl) 81:286-291.

Wirz-Justice A, Haug HJ, Cajochen C (2001) Disturbed circadian restactivity cycles in schizophrenia patients: an effect of drugs? Schizophr Bull 27:497-502.

Wurmbach E, Yuen T, Ebersole BJ, Sealfon SC (2001) Gonadotropinreleasing hormone receptor-coupled gene network organization. J Biol Chem 276:47195-47201.

Wurmbach E, Gonzalez-Maeso J, Yuen T, Ebersole BJ, Mastaitis JW, Mobbs CV, Sealfon SC (2002) Validated genomic approach to study differentially expressed genes in complex tissues. Neurochem Res 27:1027-1033.

Yuen T, Zhang W, Ebersole BJ, Sealfon SC (2002a) Monitoring G-proteincoupled receptor signaling with DNA microarrays and real-time polymerase chain reaction. Methods Enzymol 345:556-569.

Yuen T, Wurmbach E, Pfeffer RL, Ebersole BJ, Sealfon SC (2002b) Accuracy and calibration of commercial oligonucleotide and custom cDNA microarrays. Nucleic Acids Res 30:e48.

Yuen T, Wurmbach E, Ebersole BJ, Ruf F, Pfeffer RL, Sealfon SC (2002c) Coupling of $\mathrm{GnRH}$ concentration and the $\mathrm{GnRH}$ receptor-activated gene program. Mol Endocrinol 16:1145-1153.

Zhang D, Weinstein H (1993) Signal transduction by a $5-\mathrm{HT}_{2}$ receptor: a mechanistic hypothesis from molecular dynamics simulations of the three-dimensional model of the receptor complexed to ligands. J Med Chem 36:934-938. 